\title{
Tinjauan Literature Review Produksi Bersih Pada Agroindustri Kelapa di Kabupaten Indragiri Hilir- Riau
}

\section{Siti Wardah}

Program Studi Teknik Industri,Universitas Islam Indragiri

Jln.ProvinsiParit1 Tembilahan-IndragiriHilir-Riau

Email : sitiwardahst@yahoo.co.id

\begin{abstract}
The potential of coconut plantation in Indragiri Hilir Regency is very potential so that the development of plantations with agro-industry approach is an alternative choice that must be developed, in line with economic and trade development in the globalization period which is very demanding the efficiency and effectiveness of the business. In line with the growth of coconut agro industry needs a study on environmental management. Therefore this study aims to assess the potential of clean production in coconut agro-industry in order to challenge the future agroindustry is able to run in harmony with the environment. The method of this research is a literature review whose data are sourced from various national and international journals of other sources such as Books, reports. The result of the review literature review resulted that there are several alternatives that can be done to produce clean production in integrated coconut agroindustry and feasible to be applied. As a suggestion for further research is still need further development because along the development of new product of coconut so as to get product of coconut agroindustry which is competitive.
\end{abstract}

\begin{abstract}
Abstrak
Potensi perkebunan kelapa di Kabupaten Indragiri Hilir yang sangat potensial sehingga Pembangunan Perkebunan dengan pendekatan agroindustri merupakan pilihan alternatif yang harus dikembangkan, sejalan dengan perkembangan ekonomi dan perdagangan di era globalisasi yang sangat menuntut adanya efisiensi dan efektivitas usaha. Sejalan dengan bertumbuhnya agroindustri kelapa perlu adanya kajian tentang pengelolaan lingkungan. Oleh karena itu penelitian ini bertujuan untuk mengkaji potensi produksi bersih pada agroindustri kelapa dalam rangka tantangan agroindustri kedepan adalah dapat berjalan selaras dengan lingkungan. Metode penelitian ini adalah tinjauan literatur (literature review) yang datanya bersumber dari berbagai jurnal nasional dan internasionalsumbersumber lain seperti Buku, laporan. Hasil dari tinjauan literatur review dihasilkan bahwa terdapat beberapa alternatif yang dapat dilakukan agar dihasilkan produksi bersih pada agroindustri kelapa terpadu dan layak untuk diaplikasikan. Sebagai saran untuk penelitian selanjutnya adalah masih memerlukan pengembangan lebih lanjut karena seiring perkembangan produk baru kelapa sehingga didapatkan produk agroindustri kelapa yang berdaya saing.
\end{abstract}




\section{Pendahuluan}

Pembangunan perekonomian di Kabupaten Indragiri Hilir Provinsi Riau sangat berkaitan erat dengan pembangunan Perkebunan, mengingat Kabupaten Indragiri Hilir sampai sekarang masih merupakan Kabupaten yang sebagian besar masyarakatnya adalah petani kelapa. Pembangunan Perkebunan dengan pendekatan agroindustri merupakan pilihan alternatif yang harus dikembangkan, sejalan dengan perkembangan ekonomi dan perdagangan di era globalisasi yang sangat menuntut adanya efisiensi dan efektivitas usaha. Upaya untuk mendukung pembangunan pertanian tersebut adalah pengembangan agroindustri komoditas perkebunanan.

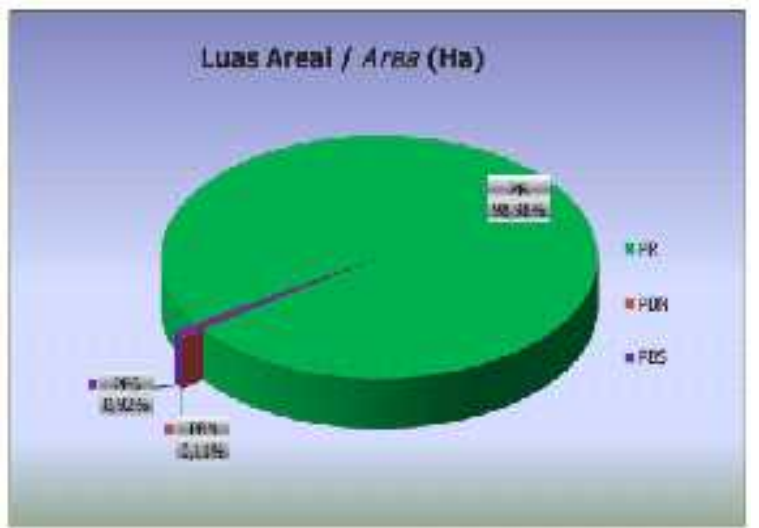

Gambar 1. Perbandingan Luas Areal dan Produksi Kelapa Menurut Status Pengusahaan Tahun 2015 (Direktorat Jenderal Perkebunan, 2016)

Komoditas perkebunan kelapa saat ini menjadi komoditas strategis di indonesia dengan luas 3.566.103 Hektar. Perbandingan Luas Areal dan Produksi Kelapa Menurut
Status Pengusahaan Tahun 2015 dapat dilihat pada Gambar 1 bahwa 98,98 \% adalah perkebunan milik rakyat. di kabupaten Indragiri Hilir adalah komoditas kelapa. Dari total 3.566.103 Hektar luas perkebunan kelapa rakyat secara nasional (Data Direktorat Jenderal Perkebunan Tahun 2016), 430.068 Hektar atau 12,06 \% diantaranya berada di Kabupaten Indragiri Hilir. Kabupaten Indragiri hilir sebagai hamparan kelapa terluas di Indonesia. Kondisi ini menunjukkan bahwa kelapa sebagai salah satu komoditas perkebunan yang bernilai ekonomis tinggi yang dapat dimanfaatkan Berdasarkan data Direktorat Jenderal Perkebunan Tahun 2016 bahwa produksi kelapa di Kabupaten Indragiri Hilir 392.752 Ton/Tahun. 


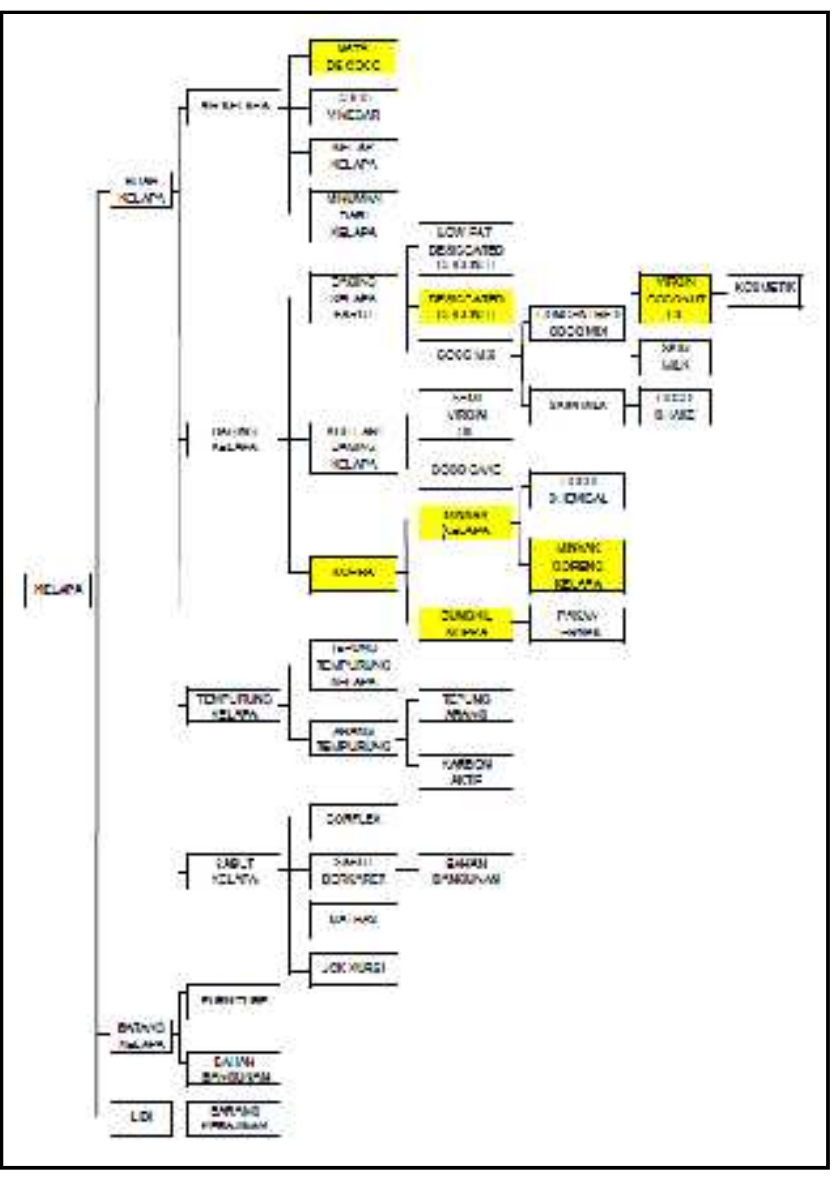

Gambar 2. Pohon Industri Kelapa

Irawadi Jamaran (2014) mengatakan bahwa Tanaman kelapa sudah tersedia luas di Indonesia, tinggal dipilih usaha yang paling sesuai dengan pelaku dan pengguna.

Beberapa turuna kelapa dapat dilihat pada Gambar 2. Produksi perspektif yang dapat dikembangkan adalah minyak kelapa (Probowati, 2011). Oleh karena itu dengan pengembangan agroindustri akan mengakibatkan semakin besarnya limbah yang dihasilkan. Produksi agroindustri berkelanjutan mewajibkan para pelaku industry memberikan perlindungan terhadap lingkungan. Pada masa kini produksi bersih banyak diterapkan karena pemerintah sudah sangat tegas dalam menindak para pelaku industry yang membuang limbahnya tanpa pengolahan yang tepat. Pembangunan agroindustri yang menerapkan konsep produksi bersih akan mendapatkan banyak keuntungan dilihat dari segi lingkungan maupun dari segi ekonomi (Nastiti, 2017). Dari berbagai penelitian Limbah yang dihasilkan dari agroindustri minyak kelapa adalah sabut kelapa, air kelapa, tempurung dan wastewater. Berdasakan hal tersebut, penulisan bertujuan untuk mengkaji potensi produksi bersih pada agroindustri kelapa dalam rangka tantangan agroindustri kedepan adalah dapat berjalan selaras dengan lingkungan.Metode penelitian ini adalah tinjauan literatur (literature review) yang datanya bersumber dari berbagai jurnal nasional dan internasionalsumber-sumber lain seperti Buku, laporan penelitian yang relevan.

\section{Tujuan}

Tujuan dari Tinjauan Literature Review Produksi Bersih Pada Agroindustri Kelapa di Kabupaten Indragiri Hilir-Riau adalah memperkenalkan konsep produksi bersih pada agroindustri kelapa

\section{Ruang Lingkup}

Agroindustri kelapa sangat luas dan kompleks, sehingga dalam penelitian ini, dilakukan pembatasan masalah agar permasalahan tersebut dapat lebih spesifik. 
Ruang lingkup penelitian yaitu sebagai berikut :

1. Melakukan tinjauan literatur tentang pemilihan prospek agroindustri dan prospek produk samping agroindustri

2. Tinjauan literature deskripsi proses, identifikasi limbah dan opsi produksi bersih serta studi kelayakan opsi produksi bersih.

\section{Metodologi Penelitian}

Kajian penelitian ini dilakukan di Kabupaten Indragiri Hilir, dimana pendekatan utama dari penelitian ini adalah seperti pada Gambar 2.

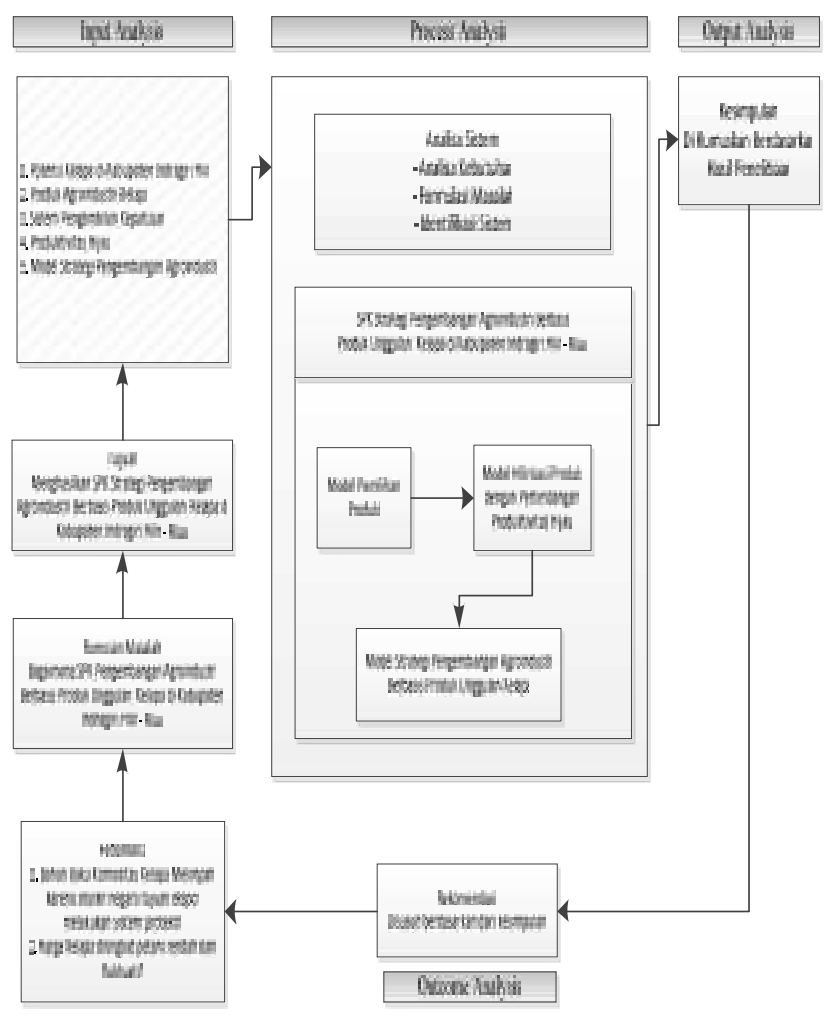

Gambar 2. Kerangka Pemikiran

\section{Hasil dan Pembahasan}

\subsection{Deskripsi Proses Produksi dan Opsi Produksi Bersih}

Bahan baku yang digunakan dalam unit pengolahan minyak kelapa dapat berupa daging buah kelapa basah maupun yang sudah kering atau dikenal dengan nama kopra. Daging buah kelapa ini diperoleh dari buah kelapa butiran hasil dari beberapa varietas unggul yaitu kelapa dalam atau kelapa hibrida. Penggunaan daging kelapa segar sebagai bahan baku akan menghasilkan perbedaan pada proses produksi dari perusahaan dengan skala mikro (rumah tangga) dan perusahaan kecil yang menggunakan peralatan yang lebih modern. Pada usaha skala mikro proses ekstraksi dilakukan pada santan, sedangkan perusahaan dengan pabrik skala kecil proses ekstraksi minyak dilakukan pada hasil penggilingan kelapa. Kapasitas produksi minyak kelapa untuk skala menengah berkisar antara $600 \mathrm{~kg}$ minyak kelapa setiap produksi membutuhkan sekitar 2 ton daging kelapa segar.

Pengolahan minyak kelapa dengan menggunakan bahan baku daging buah kelapa segar merupakan cara yang sering digunakan petani kelapa. Secara umum urutan proses produksi minyak kelapa sebetulnya hampir sama, meskipun dikerjakan secara tradisional ataupun dengan teknik yang lebih modern baik oleh industri kecil maupun industri skala menengah atau besar. Inti dari proses produksi tersebut 
adalah memisahkan minyak kelapa dari buah kelapa. Minyak kelapa dapat dipisahkan (diekstrak) langsung dari daging kelapa segar disebut sebagai cara basah, atau diekstrak dari daging kelapa yang terlebih dulu dikeringkan (kopra) yang disebut cara kering. Kandungan minyak pada daging buah kelapa tua diperkirakan mencapai $30 \%-35 \%$.

Ada peralatan utama yang digunakan dalam unit pengolahan minyak kelapa yaitu peralatan penggiling untuk menggiling atau memarut daging kelapa segar, peralatan pemeras untuk mengepress bungkil kelapa yang masih mengandung minyak dan peralatan penggerak untuk menggerakkan mesin pengepress. Tungku dan alat penggorengan (wajan) juga diperlukan dalam proses produksi ini. Tungku ini berguna untuk melakukan penggorengan dalam rangka memisahkan air dan minyak kelapa dari daging kelapa yang sudah digiling halus.

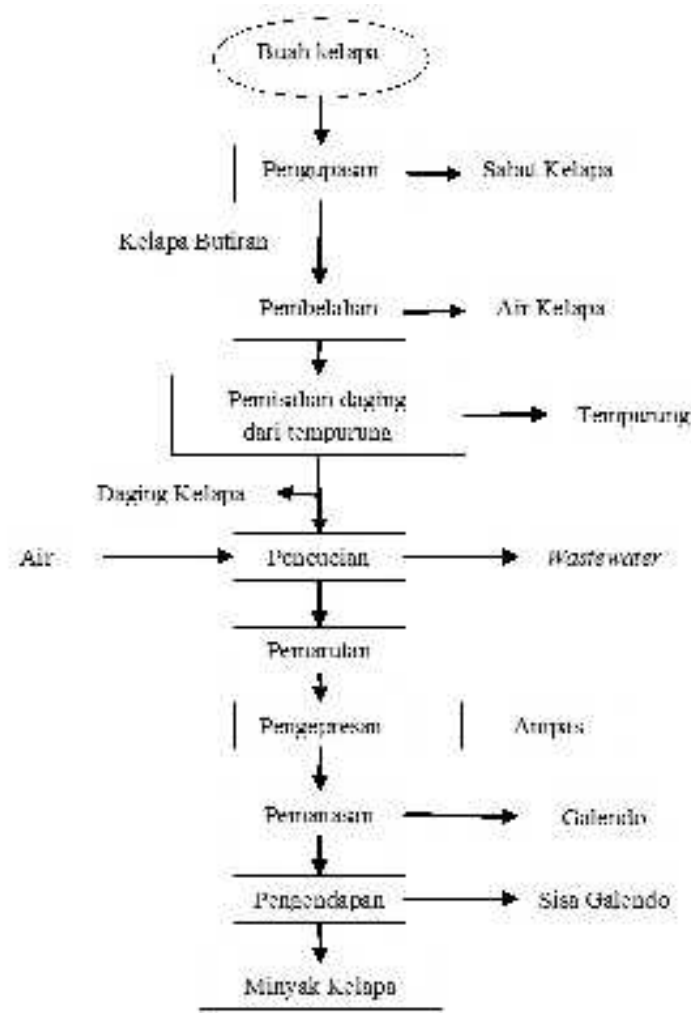

Gambar 3: Diagram Alir Proses Produksi

Minyak Kelapa (Prabonowati, 2011)

Proses ekstraksi minyak kelapa dapat dijelaskan dengan langkah-langkah berikut: pertama, daging kelapa segar dicuci bersih dan kemudian digiling atau diparut dengan penggilingan atau parutan. Potongan daging kelapa tersebut selanjutnya digiling, dan dimasukkan dalam wajan penggorengan yang telah berisi minyak goreng panas pada suhu $110^{\circ} \mathrm{C}-120^{\circ} \mathrm{C}$ selama $15-40$ menit. Proses ini tergantung dari suhu dan rasio daging kelapa giling dan minyak kelapa yang digunakan untuk menggoreng. Hal yang harus diperhatikan selama proses penggorengan, wajan jangan diisi terlalu penuh karena daging kelapa giling yang 
digoreng cepat menguap dan menghasilkan minyak sehinga jika terlalu penuh akan bisa tumpah. Peningkatan suhu dalam wajan akan menghasilkan uap air dari penggorengan daging kelapa giling. Uap ini sudah tidak berarti lagi apabila penggorengan sudah selesai dan daging kelapa giling berubah warnan dari warna kekuning-kuningan menjadi kecoklatan.

Upaya untuk mempercepat pemisahan butiran kelapa panas dengan unsur minyak dapat dilakukan dengan cara mengaduk dengan menggunakan sendok panjang. Butiran yang sudah berpisah dari minyak kemudian dikeluarkan dari wajan dengan menggunakan penyaring dan minyak hasil penggorengan ditampung.. Berdasarkan dari penelitiaan Probowati (2011) bahwa diagram alir pembuatan minyak kelapa seperti pada Gambar 3.Berikut adalah identifikasi limbah dan opsi produksi bersih pada setiap proses

\section{a. Pengupasan}

\section{- Deskripsi Proses}

Pada produksi minyak kelapa yang akan digunakan adalah berupa kelapa beberapa varietas unggul yaitu kelapa dalam atau kelapa hibrida. Pada saat pengupasan maka dihasilkan kesetimbangan massa seperti pada Gambar 4.

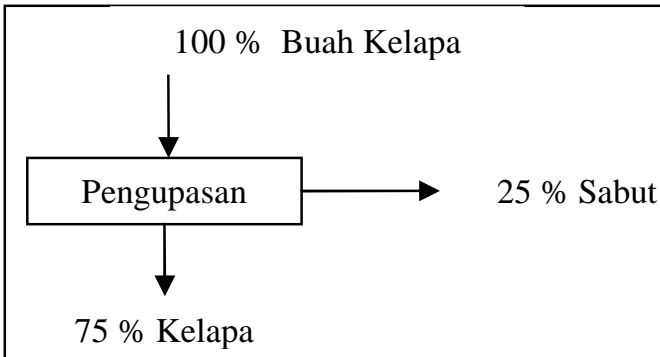

Gambar 4. Sistem Kesetimbangan

Massa pada proses pengupasan

- Identifikasi Limbah

Pada tahap ini muncul hasil samping berupa $25 \%$ sabut kelapa.

\section{- Opsi Produksi Bersih}

Hasil samping berupa sabut kelapa dapat dimanfaatkan sebagai adsorben(Rahayu, Purnavita, \& Sriyana, 2014) dan untuk industri serat sabut kelapa(Probowati, 2011)

\section{b. Pembelahan}

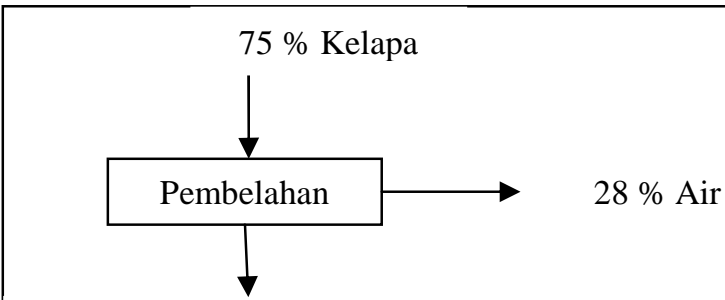

$47 \%$ Kelapa yang sudah

Gambar 5. Sistem Kesetimbangan

Massa pada proses pembelahan

\section{- Deskripsi Proses}

Pada proses pembelahan bertujuan untuk menghilangkan air kelapanya. Adapun kesetimbangan Massa seperti pada Gambar 5.

- Identifikasi Limbah 
Pada proses pembelahan dihasilkan hasil samping berupa air kelapa sebanyk $28 \%$ air.

\section{- Opsi Produksi Bersih}

Pada beberapa penelitian (Probowati, 2011), (Rini Hakimi , Vonny Indah Mutiara, 2005), (Rini Hakimi, 2006), (Romli, n.d.), (Hendrawati, 2016) bahwa output produksi bersih hasil sampingnya dapat dijadikan nata de coco.

\section{c. Pemisahan daging dari tempurung}

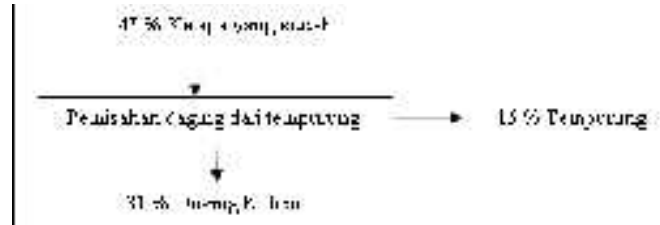

Gambar 6. Sistem Kesetimbangan

Massa pada proses Pemisahan daging dari tempurung

\section{- Deskripsi Proses}

Setelah dilakukan pembelahan, kemudian proses pengambilan daging kelapa. Adapun kesetimbangan Massa seperti pada Gambar 6.

\section{- Identifikasi Limbah}

Pada proses pemisahan daging dari Tempurung dihasilkan hasil samping berupa tempurung sebanyak $16 \%$.

\section{- Opsi Produksi Bersih}

Berdasarkan hasil penelitian (Arena, Lee, \& Clift, 2016)dan
(Subadra, Setiaji, \& Tahir, 2005)bahwa hasil samping yang prospektif adalah dengan karbon aktif

\section{d. Pencucian}

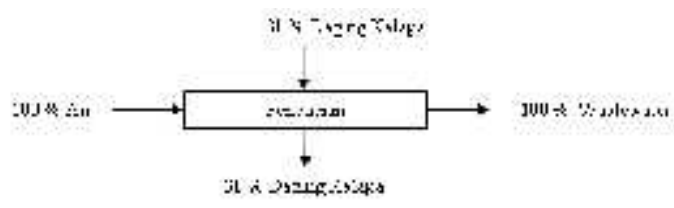

Gambar $\quad 7 . \quad$ Sistem

Kesetimbangan Massa pada

proses pencucian

\section{- Deskripsi Proses}

Setelah dilakukan pemisahan daging dari tempurungnya, kemudian dilakuakn proses pencucian daging kelapa dengan persentase $100 \%$. Adapun kesetimbangan Massa seperti pada Gambar 7.

- Identifikasi Limbah

Pada proses pencucian dihasilakan wastewater yang berupa campuran air dan lemak kelapa dengan kesetimbangan masa seperti pada Gambar.

\section{- Opsi Produksi Bersih}

Untuk mengurangi hasil sampingnya dilakukan dengan penggunaan teknik pencucian arus balik co current atau single cascade untuk meminimalkan penggunaan air(Romli, n.d.). dismaping itu wastewater mengandung 1,5\% lemak dan mineral yang sangat berharga, seperti zat besi, natrium, kalium, 
magnesium, kalsium dan sejumlah fosfor kecil. Ada pasar yang cukup besar misalnya di Taiwan, dan teknologinya tersedia di Filipina, Thailand dan China. Promosi transfer teknologi melalui usaha patungan dan penelitian lokal dan pengembangan dapat mengurangi limbah dan meningkatkan keuntungan(Kumar, 2003)

\section{e. Pengepresan}

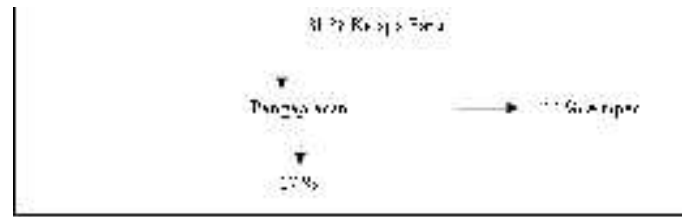

Gambar 8. Sistem Kesetimbangan Massa pada prosesPengepresan

\section{- Deskripsi Proses}

Untuk mendapatkan santannya dilakukan pengepresan dengan menggunakan alat pengepres dengan proses kesetimbangan massa seperti pada Gambar 8.

\section{- Identifikasi Limbah}

Pada proses pengepresan dihasilkan ampas kelapasebanyak $14 \%$.

\section{- Opsi Produksi Bersih}

Ampas kelapa dapat dimanfaatkan sebagai pakan ternakdan tepung kelapa(Nurdiani, 2015)

\section{f. Pemanasan}

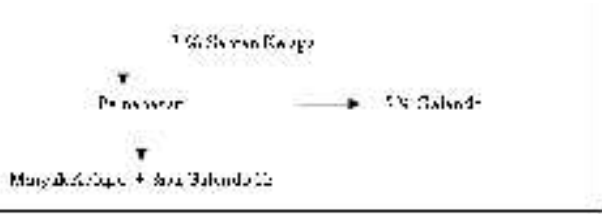

Gambar 9. Sistem Kesetimbangan Massa pada proses Pemisahan daging dari tempurung

\section{- Deskripsi Proses}

Setelah dilakukan pengepresan, kemudian dilakukan pemanasan untuk memperoleh minyak kelapa dengan cara santan dipanaskan untuk menguapkan air dan menggumpalkan bagian bukan minyak yang disebut blonddengan kesetimbangan massa seperti pada Gambar 9.

\section{- Identifikasi Limbah}

Pada proses pemanassan dihasilkan hasil samping berupa galendo sekitar 5 $\%($ Nurdiani, 2015).

\section{- Opsi Produksi Bersih}

Pemanfaatan Galendo di Kabupaten Ciamis adalah sebagaimakanan khas (Nurdiani, 2015)

\section{g. Pengendapan}

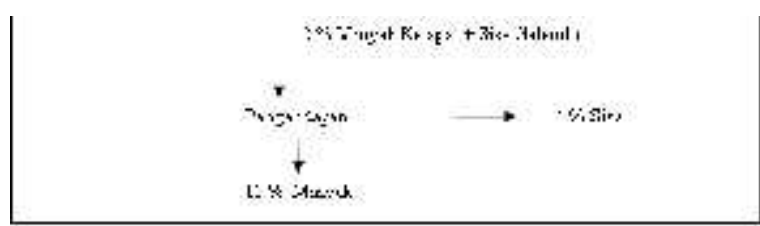

Gambar 10. Sistem Kesetimbangan Massa pada proses Pengendapan

\section{- Deskripsi Proses}

Setelah dilakukan pemanasan dilakukan proses pengendapan agar diperoleh minyak 
kelapa tanpa ada sisa galendonya dengan Sistem Kesetimbangan Massa pada proses Pengendapan seperti pada Gambar 10.

\section{- Identifikasi Limbah}

Pada proses pengendapan dihasilkan hasil samping berupa galendo sekitar kurang lebih $1 \%$.

\section{- Opsi Produksi Bersih}

Pemanfaatan Galendo di Kabupaten Ciamis adalah sebagai makanan khas (Nurdiani, 2015)

\subsection{Studi Kelayakan}

Tujuan dari studi kelayakan agroindustri kelapa adalah menentukan opsi-opsi produksi bersih yang mungkin diterapkan pada agroindustri kelapa. bila ditinjau dari kemudahan melaksanakan, opsi biaya dan dilihat dari sisi manfaatnya. Apabila opsi tersebut diterapkan serta dampak yang ditimbulkan terhadapa lingkungan setelah opsi tersebut diterapkan.

Pada studi kelayakan secara ekonomi dengan tinjauan literature review dari penelitiaan Rini Hakimi (2006), Kuswanto (2012), (Wardanu \& Uliyanti, 2015) dan Hendrawati (2016), didalamnya memasukkan analisis financial untuk opsi produksi bersih yang dapat dilihat pada Tabel1.

\section{Kesimpulan dan Saran}

1. Kesimpulan

Agroindustri kelapa dapat diarahkan pada produksi bersih. Hal ini dapat dilihat dari hasil penelitian opsi produk samping yang perspektif dan ramah lingkungan seperti Nata de Coco, Karbon Aktif dan Serat Sabut Kelapa dan dari studi kelayakan bahwa layak untuk diaplikasikan.

2. Saran

Produksi bersih dari tinjauan literatur ini masih memerlukan pengembangan lebih lanjut karena seiring perkembangan produk baru kelapa sehingga didapatkan produk agroindustri kelapa yang berdaya saing. 


\section{Daftar Pustaka}

Abner lay dan Patrik M. Pasang. (2012).

STRATEGIES

AND

IMPLEMENTATION

OF

DEVELOPMENT OF FUTURE

COCONUT PRODUCTS, 11(1), 1-22.

Arena, N., Lee, J., \& Clift, R. (2016). Life

Cycle Assessment of activated carbon

production from coconut shells, 125 ,

68-77.

https://doi.org/10.1016/j.jclepro.2016.0 3.073

Austin, J. E. (1992). Agroindustrial Project Analysis.Alade, A.O., Amuda, O.S., Bello, M.O., 2012. Life Cycle Inventory Analysis (LCIA) of production of activated carbons from selected agricultural materials. Pollution 44, 7275e 7279

Bansal, R.C., Goyal, M., 2005. Activated Carbon Adsorption.

Brander, M., Tipper, R., Hutchison, C., Davis, G., (2009). Consequential and Attributional Approaches to LCA: a Guide to Policy Makers with Specific Reference to Greenhouse Gas LCA of Biofuels. Tech. Paper TP-090403. Ecometrica Press Cagnon, B., Py, X.,

Stoeckli, F., 2003. The effect of the carbonization/activation procedure on the microporous texture of the subsequent char sand active carbons. Micro. Meso. Mater. 57, 273e282.

Budiman, C., Massie, J., \& Wullur, M. (2015). Identifikasi Desain Jaringan Manajemen Rantai Pasok Kopra Di Kota Manado, 3(2), 65-76.
Clavreul, J., Guyonnet, D., Christensen, T.H., 2012. Quantifying uncertainty in LCAmodelling of waste management systems. Waste Manag. 32, 2482e2495. http://dx.doi.org/10.1016/j.wasman.201 2.07.008. Clift, R., Doing, G., Finnveden, G., 2000. The Application of Life Cycle Assessment to Integrated Solid Waste Management Part 1Methodology. Institution of Chemical Engineers Trans IChemE 78,B

Damanik, S. (2007). Strategi Pengembangan Agribisnis Kelapa ( Cocos nucifera ) untuk Meningkatkan Pendapatan Petani di Kabupaten Indragiri Hilir , Riau, 6(2), 94-104.

Direktorat Jenderal Perkebunan. (2016). Statistik Perkebunan Indonesia.

Devi, L., Ptasinski, K.J., Janssen, F.J.J.G., 2005. Pretreated olivine as tar removal catalyst for biomass gasifiers: investigation using naphthalene as model biomass tar. Fuel Process. Technol. 86, 707e730. In: http://dx.doi.org/10.1016/j. fuproc.2004.07.001.

EC-IPPC, 2006. Reference Document on the Best Available Techniques for Large Combustion Plants. European Commission e Integrated Pollution Preventionand Control.

Gunarta, I. K. (2012). Rancang bangun model pendukung keputusan pengembangan agroindustri crude palm oil berbasis spasial.

Direktorat Jenderal Perkebunan. (2016). Statistik Perkebunan Indonesia.Hakimi, Rini. 2006. Penerapan Produksi Bersih (Cleaner Production) pada Industri Nata de Coco. Jurnal Teknik Mesin Vol 3, No 2, Desember 2006 
Hendrawati, T. Y. (2016). ANALISIS

KELAYAKAN INDUSTRI KELAPA

TERPADU, $8(2)$.

Kumar, S. (2003). Desiccated coconut industry of Sri Lanka : opportunities for energy efficiency and environmental protection, 44, 2205-2215. https://doi.org/10.1016/S01968904(02)00235-2

Kusuma, P.T.W., 2012. Analisis Kelayakan Finansial Pengembangan Usaha Kecil Menengah (UKM) Nata de coco di Sumedang, Jawa Barat.Jurnal Inovasi dan KewirausahaanVolume 1 No. 2 Mei 2012 Hal. 113-12.

Kuswanto. (2012). Analisa Kelayakan Financial Usaha Pengolahan Produk Turunan Kelapa di Provinsi Jambi.

Masella, C.P. (2011). Analisa Kelayakan Teknis dan Finansial Produksi Karbon Aktif Granula Tempurung Kelapa. Skripsi. Fakultas Teknologi Pertanian. Universitas Brawijaya. Malang.

Indrasti, N dan Fauzi, A, (2009). Produksi Bersih, Bogor:IPB Press

Nurdiani, D. M. (2015). Profitabilitas Usaha Pengolahan dan Nilai Tambah Produk Minyak Kelapa (Studi Kasus: Tiga Usaha Pengolahan Minyak Kelapa di Kabupaten Ciamis).

Palungkun R. 1993. Aneka Produk Olahan Kelapa. Jakarta : Penebar Swadaya

Probowati, B. D. (2011). Perancangan Model Rantai Pasokan Untuk Agroindustri Kelapa Terpadu Dalam Usaha Kecil.

Rahayu, L. H., Purnavita, S., \& Sriyana, H.
Y. (2014). Akademi Kimia Industri “ Santo Paulus " Semarang, 10(1), 4753.

Rinaldi H. 2008. Analisis Nilai Tambah Agroindustri Kelapa Studi Kasus: Agroindustri Kelapa di Kabupaten Ciamis [tesis]. Bandung : Program Pasca Sarjana ITB

Rini Hakimi, D. B. (2006). APLIKASI PRODUKSI BERSIH ( CLEANER PRODUCTION ) PADA INDUSTRI NATA DE COCO, (1).

Rini Hakimi, Vonny Indah Mutiara, D. B. (2005). PENERAPAN PRODUKSI BERSIH ( C L E A N E R P R O D U C T I O N ) PADA INDUSTRI NATA DE COCO DI KOTA PADANG (IPTEKS).

Romli, M. (n.d.). CLEANER PRODUCTION IN THE MANUFACTURING OF VIRGIN COCONUT OIL, 49-57.

Subadra, I., Setiaji, B., \& Tahir, I. (2005). ACTIVATED CARBON PRODUCTION FROM COCONUT SHELL WITH ( NH 4 ) HCO 3 ACTIVATOR AS AN ADSORBENT IN VIRGIN COCONUT OIL, (September), 1-8.

Umar, H. 2009. Studi Kelayakan Bisnis. Jakarta : PT Gramedia Pustaka Utama.

Wardanu, A. P., \& Uliyanti. (2015). ADDED VALUE ANALYSIS AND FEASIBILITY STUDY OF NATA DE COCO AGROINDUSTRY IN KETAPANG DISTRICS WEST BORNEO, 7(2). 